\title{
Comparison of chemical properties, antioxidant capacity, and phenolic acids of autoclaved and unautoclaved ground mustard seeds
}

\author{
Veli GÖK ${ }^{1 *}$ (D), Muhammed Yusuf ÇAĞLAR², Oktay TOMAR ${ }^{3}$ (D)
}

\begin{abstract}
This present research, the proximate analyses, the antioxidant capacity and phenolic composition of Sinapis alba (yellow mustard seed), Brassica nigra (black mustard seed), Brassica juncea (brown mustard seed) and their autoclaved samples were evaluated. The antioxidant capacity of mustard seeds was analysed by examining antiradical activity, $\mathrm{Fe}^{2+}$ chelating activity, $\mathrm{H}_{2} \mathrm{O}_{2}$ scavenging and total phenolics. The mustard seeds were autoclaved to inhibit myrosinase activity. The level of antioxidant capacity and the phenolics of the mustard seeds were increased with autoclave treatment. The antiradical activity of mustard seeds were determined ACL $\times Y M(0.810)$ followed by ACL×BRM (0.750), UNACLxYM (0.680), UNACLxBRM (0.600), ACLxBLM (0.590) and UNACLXBLM $(0.450)$ types respectively $(P<0.05)$.
\end{abstract}

Keywords: Sinapis alba; Brassica nigra; Brassica juncea; antioxidant capacity; phenolic composition; mustard seeds.

Practical Application: The level of antioxidant capacity and the phenolics of the mustard seeds were increased with autoclave treatment. Autoclave process influenced hyroxybenzoic acid content of mustard seeds positively except for Brassica nigra sample. Autoclave treatment increased the antioxidant activity of mustard seeds significantly. The mustard seeds wide range antioxidant capacity and they compared Sinapis alba generally has highest value all of the value.

\section{Introduction}

Over the century medicinal herbs and spices have been used for many different purposes including treatments of illness, relaxing mentally, enrichment of taste and aroma of foods. Spices and herbs have been utilized for preservation of foods and beverages by their antimicrobial activity and antioxidant activities (Peter, 2006). They include a lot of antioxidant components. Their antioxidant and antimicrobial activity come from their phytochemicals (Embuscado, 2015).

The mustard plant takes part in the Cruciferae (Brassicaceae) family. Mustards have many nutrients and they have phytochemicals such as glucosinolates and phenolic compounds (Jahangir et al., 2009).

Mustard seeds include various secondary metabolites such as glucosinolates (Engels et al., 2012). Glucosinolates include nitrogen and sulfur. These organic compounds comprise of plants of the Brassicaceae family (Oram et al., 2005). The myrosinase enzyme hydrolyses glucosinolates to produce isothiocyanates, oxazolidine-2-thiones, nitriles and epithionitriles (Bongoni et al., 2014). Mustard seeds also have phenolic acids such as Hydroxycinnamic acids, hydroxycinnamoylquinic acids, sinapic acids, ferulic acids and $p$-coumaric acids. These secondary metabolites showed antimicrobial (Nilson \& Holley, 2012) and antioxidant characteristics ( $\mathrm{Lu}$ et al., 2011).

In this study chemical composition of mustard seeds, phenolic compounds of mustard seeds and antioxidant activity of mustard seeds were determined.

\section{Material and methods}

\subsection{Material}

The deodorized mustard powders were prepared by Luciano et al. (2011) method. The mustards powders were obtained from Bagdat Food Co. (Turkey). The ground mustard seeds stored them in sealed packaging to prevent their exposure to light. The 200 grams of yellow, brown, and black mustard seeds were used for application. The mustards powder's packages were removed. The powders were spread out in layers of $2 \mathrm{~cm}$ onto stainless steel trays. At this point, the mustard seeds divided into two groups. Group 1 was left untreated (unautoclaved, UNACL), and Group 2 was autoclaved (ACL) at $121^{\circ} \mathrm{C}$ for $15 \mathrm{~min}$ at $1 \mathrm{~atm}$ pressure to increase phenolic activity.

The treatments tested had the following composition: UNACL $\times$ YM prepared with unautoclaved yellow mustard, $A C L \times Y M$ prepared with autoclaved yellow mustard; UNACL $\times B R M$ prepared with unautoclaved brown mustard, ACL $\times$ BRM prepared with autoclaved brown mustard; UNACL $\times$ BLM prepared with unautoclaved black mustard, ACL $\times$ BLM prepared with autoclaved black mustard.

\subsection{Chemical composition of mustard}

Proximate analyses of samples (protein (\%), moisture (\%), oil (\%), carbonhydrate (\%), dietary fiber (\%), ash content (\%)) were analyzed according to Association of Official Analytical Chemists (2000) methods. 


\subsection{Determination of phenolic content of mustard seeds}

Preparation of phenolic compounds standard

1000 ppm stock solutions were prepared from phenolic acids for gallic, $\mathrm{p}$-hydroxybenzoic, syringic, caffeic, $\mathrm{p}$-cumaric or cinnamic acids. All standards were dissolved with methanol. Intermediate inventories are prepared from these standards. A mixture of these compounds was prepared to separate 6 phenolic compounds at the head. The retention time for each standard has been determined.

\section{Extraction of mustard seed}

In order to determine the phenolic compound profile of mustard seed, sample preparation process was performed based on the methods applied by Shui \& Leong (2002) and Poyrazoğlu et al. (2002).

\section{HPLC analysis}

To determine the phenolic compound profile of mustard seeds, sample preparation was performed based on the methods applied by Shui \& Leong (2002) and Poyrazoğlu et al. (2002). A certain amount of mustard flour extract was filtered through $0.45 \mu \mathrm{m}$ filter and introduced into the HPLC apparatus under the chromatographic conditions set forth below (Table 1).

The column was Hichrom, HI-5C18 (5 - m, 4.6 ×250 mm), the solvents were distilled water (Solvent A) and Methanol (Solvent B). The oven temperature was set at $30^{\circ} \mathrm{C}$. The injection volume of sample was $5-15 \mu \mathrm{L}$. The flow rate is $1 \mathrm{~mL} /$ minute and the wavelength is $280 \mathrm{~nm}$.

\subsection{Determination of antioxidant activities of mustard seeds}

\section{Preparation of sample extracts}

The method applied by Koç (2017) was used for preparation of mustard extracts.

Table 1. High-performance liquid chromatography (HPLC) elution program.

\begin{tabular}{ccc}
\hline Solvent A & Solvent B & Time (minute) \\
\hline $100 \%$ & $0 \%$ & 0 \\
$90 \%$ & $10 \%$ & 10 \\
$70 \%$ & $30 \%$ & 40 \\
$100 \%$ & $0 \%$ & 50 \\
\hline
\end{tabular}

\section{Total phenolic content}

The total phenolic content of the samples measured by Singleton \& Rossi's (1965) method. The phenolic content values were determined as $\mathrm{mg}$ Gallic Acid (GA)/g and analyzed at a wavelength of $765 \mathrm{~nm}$.

\section{Free radical scavenging activity}

Free radical scavenging activity of the samples was determined by partial modification of the method of Brand-Williams et al. (1995).

$\mathrm{Fe}^{2+}$ chelating activity

The methods applied by Rival et al. (2001) were utilized to conclude the chelating activity of the samples.

$\mathrm{H}_{2} \mathrm{O}_{2}$ inhibition effect

The methods applied by Ruch et al. (1989) were utilized to evaluate the ability of mustard extracts to remove $\mathrm{H}_{2} \mathrm{O}_{2}$. The analysis conducted with spectrophotometer and wavelength was $230 \mathrm{~nm}$.

\subsection{Statistical analysis}

Statistical evaluation of the samples was performed by SPSS 16.0 program. One way ANOVA test was used for the determination of the differences between means. The differences between samples were determined by using the Duncan test. The study was carried out with three replications.

\section{Results and discussion}

\subsection{Protein (\%), moisture (\%), oil (\%), carbonhydrate (\%), dietary fiber (\%), ash content (\%) of mustard seeds}

The chemical composition of the three analyzed mustard varieties (yellow, black and brown mustard seeds) is shown in Table 2 .

When protein and oil contents of samples were compared (Table 2) it was found to be yellow mustard seed had a higher protein content value (33.60\%) than that of brown mustard seed (33.20\%) and black mustard seed (27.80\%). Unlike to this, the oil content of black mustard seed was higher (41.40\%) than that of brown mustard seed (36.20\%) and yellow mustard seed (29.10\%) of oil (Table 2). Also, another studies of results supported to oil and protein content value of this study (Abul-Fadl et al., 2011; Sharma et al., 2012).

Table 2. Chemical composition of mustard seeds (\%).

\begin{tabular}{|c|c|c|c|c|c|c|}
\hline Mustard Type & Oil & Protein & Ash & Moisture & Dietary Fiber & $\begin{array}{c}\text { Total } \\
\text { Carbohydrates }\end{array}$ \\
\hline YM & 29.1 & 33.6 & 5.3 & 8.6 & 5.87 & 17.53 \\
\hline $\mathrm{BRM}$ & 36.2 & 33.2 & 5.4 & 8.2 & 6.15 & 10.85 \\
\hline BLM & 41.4 & 27.8 & 5.7 & 8.1 & 6.75 & 10.25 \\
\hline
\end{tabular}

YM: yellow mustard; BRM: brown mustard; BLM: black mustard. 
The analyzed mustard seeds of total carbohydrates moisture, ash, dietary fiber and which were determined as $17.53 \%, 8.60 \%$, $5.30 \%, 5.87 \%$ and in Sinapis alba; 10.85\%, 8.20\%, 5.40\%, 6.15\% in Brassica juncea; $10.25 \%, 8.10 \%, 5.70 \%, 6.75 \%$, in Brassica nigra respectively (Table 2 ).

\subsection{Phenolic compound content of mustard seeds}

Phenolic compounds which located in vegetables as free and conjugated forms (Cartea et al., 2010). Fang et al. (2008) investigated pickled leaf mustard. Researchers determined various hydroxycinnamic acids as sinapic, caffeic, p-coumaric, ferulic and along with benzoic acid derivatives as vanillic, gallic, protocatechuic and $\mathrm{p}$-hydroxybenzoic acids. In this study we identified hydroxycinnamic acid, hydroxybenzoic acid, catechin derivatives and siringic acid. This difference may be originated from different mustard part (mustard leaf, mustard seed). Fang et al. (2008) determined that the mustard leaf had p-hydroxybenzoic acid about $2.6 \mathrm{ppm}$ (free), $10.2 \mathrm{ppm}$ (alkaline hydrolosis), $5.6 \mathrm{ppm}$ (acid hydrolosis) and $15.8 \mathrm{ppm}$ (total phenolic acids). We determined hydroxybenzoic acid in mustard seeds about ACLxYM (721.65 ppm) $(P<0.05)$, UNACLxYM (605.69 ppm), UNACLxBRM (226.15 ppm) and ACLxBRM (270.42 ppm) but this phenolic acid was not detected in UNACLxBLM and ACLxBLM samples (Table 3). Furthermore, autoclave process influenced hyroxybenzoic acid content of mustard seeds positively except for Brassica nigra sample $(P<0.05)$. Hydroxybenzoic acids are found in low amounts in the content of plant foods, with the main ones being vanillic acid, gallic acid, salicylic acid, m-hydroxybenzoic acid and p-hydroxybenzoic acid,. Hydroxybenzoic acids occur as a result of a reaction chain with the $\beta$-oxidation of fatty acids from hydroxycinnamic acids. Hydroxycinnamic acids are widely found in plant products and have various properties. Among these acids, p-coumaric acid, ferulic acid, caffeic acid and o-coumaric acid have an important place (Schuster \& Herrmann 1985).

The hydroxycinnamic acid contents of the samples when compared with each other, the highest value was found in the ACLxYM (381.66 ppm) sample and the lowest in the UNACLxBLM (104.00 ppm) sample (Table 3 ). The syringic acid content of mustard seeds when compared, the highest value was observed in the ACLxYM sample (411.29 ppm) and the lowest values in the UNACLxBLM (18.30 ppm) and ACLxBLM samples $(25.58 \mathrm{ppm})(P<0.05)$. The highest catechin derivatives were found in ACLxBLM (1701.11 ppm) and ACLxBRM (1698.11 ppm) samples and the lowest catechin derivatives were found in
UNACLxBLM (679.07 ppm). Lu et al. (2011) stated on phenolics of spices ordinarily utilized in China and they didn't identified phenolic acids in Brassica nigra but they stated phenolic acids as unknown phenolic acids (5155.2 \pm 28.6 ppm). Lin \& Harnly (2010) characterized the phenolic compounds from Brassica species. In their study, phenolic compounds consisting of isorhamnetin 3-O-glucoside-7-O-glucoside hydroxycinnamoyl gentiobioses, hydroxycinnamoylmalic acids, kaempferol 3-O-diglucoside-7-Oglucoside derivatives, and hydroxycinnamoylquinic acids were determined with LC-DAD-ESI/MS. The phenolic compounds of mustard greens identified comprehensively but the phenolic compounds of mustard seeds were not identified and not determined quantitatively. Therefore this study is important for phenolic compounds content of mustard seeds.

\subsection{Antioxidant activity of mustard seeds}

Free radical scavenging activity

According to Figure 1 the antiradical activity was determined $\mathrm{ACL} \times \mathrm{YM}(0.810)$ followed by ACL $\times \mathrm{BRM}(0.750)$, UNACLxYM (0.680), UNACLxBRM (0.600), ACLxBLM (0.590) and UNACLxBLM (0.450) types respectively.

Autoclave treatment increased the antioxidant activity of mustard seeds significantly $(P<0.05)$. Blanching heat treatment method used for the cauliflower and cabbage therefore free radical scavenging activity was reduced by $23 \%$, raised by $9 \%$ respectively (Puupponen-Pimiä et al., 2003). This activity of florets and stems of broccoli were reduced with conventional and microwave heat treatments for 5 min (Zhang \& Hamauzu, 2004).

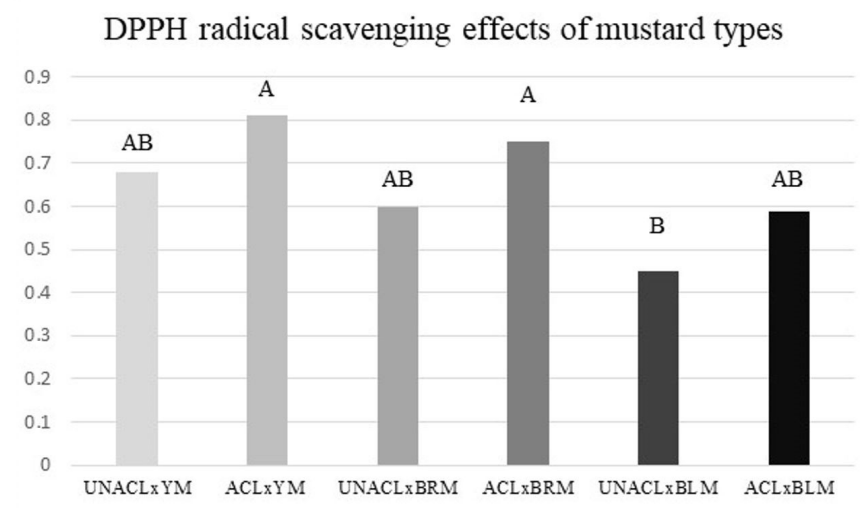

Figure 1. DPPH radical scavenging effects of mustard types. Levels not connected by same letter are significantly different $(\mathrm{p}<0.05)$. The description of the sample codes is shown in Table 3.

Table 3. Contents of phenolic acids in mustard types ( $\mu \mathrm{g} / \mathrm{g} \mathrm{DW})$.

\begin{tabular}{|c|c|c|c|c|}
\hline Group & Hydroxybenzoic acid & Hydroxycinnamic acid & Syringic acid & Catechin derivatives \\
\hline UNACL $\times Y M$ & $605.69^{\mathrm{B}}$ & $318.29^{\mathrm{B}}$ & $399.13^{\text {в }}$ & $916.54^{\mathrm{D}}$ \\
\hline $\mathrm{ACL} \times \mathrm{YM}$ & $721.65^{\mathrm{A}}$ & $381.66^{\mathrm{A}}$ & $411.29^{\mathrm{A}}$ & $1239.56^{\mathrm{C}}$ \\
\hline UNACL $\times$ BRM & $226.15^{\mathrm{D}}$ & $212.61^{\mathrm{D}}$ & $325.89^{\mathrm{D}}$ & $1416.86^{\mathrm{B}}$ \\
\hline $\mathrm{ACL} \times \mathrm{BRM}$ & $270.42^{\mathrm{C}}$ & $246.97^{\mathrm{C}}$ & $350.14^{\mathrm{C}}$ & $1698.11^{\mathrm{A}}$ \\
\hline UNACL $\times$ BLM & 0 & $104.00^{\mathrm{F}}$ & $18.30^{\mathrm{E}}$ & $679.07^{\mathrm{E}}$ \\
\hline $\mathrm{ACL} \times \mathrm{BLM}$ & 0 & $143.23^{\mathrm{E}}$ & $25.58^{\mathrm{E}}$ & $1701.11^{\mathrm{A}}$ \\
\hline
\end{tabular}

Levels not connected by same letter are significantly different $(\mathrm{p}<0.05)$. UNACL $\times$ YM: prepared with unautoclaved yellow mustard; ACL $\times$ YM: prepared with autoclaved yellow mustard; UNACL $\times$ BRM: prepared with unautoclaved brown mustard; ACL $\times$ BRM: prepared with autoclaved brown mustard; UNACL $\times$ BLM: prepared with unautoclaved black mustard; ACL $\times$ BLM: prepared with autoclaved black mustard. 
Lu et al. (2011) researched on antioxidant capacity of spices commonly consumed in China and they determined that Brassica nigra had $17.89 \%$ antiradical activity. Our results showed that Brassica nigra had $45.00 \%$ antiradical activity. This difference may be explained growing conditions of Brassica nigra and growing place. Fang et al. (2008) researched on antioxidant capacity of potherb mustard (Brassica juncea, Coss) pickling and they determined that pickling good preservation method for antioxidant of potherb mustard. Similarly we applied the autoclave process on mustard seeds to preservation of antioxidant and this process was successful on preservation of antioxidant of all mustard samples.

\section{$\mathrm{Fe}^{2+}$ Chelating Activity (FCA)}

The metal chelating capacity depends on the functional groups present in the structure of the phenolic compounds and the position and amount of these functional groups.

A significant difference was determined between the FCA of mustard seeds $(P<0.05)$. When the FCA of the mustard samples were compared, the highest values were found in the ACLxYM (56.17\%) and ACLxBRM (54.10\%) mustard seeds $(P<0.05)$ (Figure 2). In investigating the effect of the autoclave application on the chelate binding capacity of mustard, it was found that autoclaving had a positive effect in all the mustard samples and increased the FCA of the samples $(P<0.05)$. Park et al. (2017) studied on antioxidant activity of kimchi extracts during fermentation and they stated that the chelating activity of the methanol extracts decreased the $\mathrm{EC}_{50}$ value from 33.6 to $3.5 \mathrm{mg} / \mathrm{mL}$ during fermentation. On the contrary, the metal chelating ability of the water extracts enhanced significantly until fermentation with the $\mathrm{EC}_{50}$ values ranging from 38.0 to $161.3 \mathrm{mg} / \mathrm{mL}$.

\section{$\mathrm{H}_{2} \mathrm{O}_{2}$ Inhibition Activity $\left(\mathrm{H}_{2} \mathrm{O}_{2} \mathrm{IA}\right)$}

The $\mathrm{H}_{2} \mathrm{O}_{2}$ IA of mustard samples are given in Figure 3. According to Figure 3 the $\mathrm{H}_{2} \mathrm{O}_{2}$ inhibition activity was determined ACL $\times Y M(63.18 \%)$ followed by UNACLxYM (53.89\%), ACL $\times B R M$ (50.78\%), UNACLxBRM (48.78\%), ACLxBLM (47.44\%) and UNACLxBLM (43.22\%) types respectively. The autoclave application also increased the inhibitory values of the $\mathrm{H}_{2} \mathrm{O}_{2}$ in mustard $(P<0.05)$. Previous study state that the addition of autoclaved ground mustard seeds in meatball decreased lipid oxidation and autoclaved ground mustard seeds showed more antioxidant characteristics than unautoclaved ground mustard seeds (Çağlar et al., 2018).

\section{Total phenolic compound}

The correlation between phenolic substances and antioxidant activity has been demonstrated in many studies, with some showing there to be positive correlation between phenolic substances content and antioxidant activity (Price et al., 1997), and others showing there to be either no such relationship or a weak relationship between these two parameters (Lombard et al., 2005).

When the total phenolic substance contents of mustard samples were compared, the highest value was found in the
ACLxYM (28.29 mg gallic acid/g) (Figure 4) sample $(P<0.05)$. The application of autoclave was found to increase the amount of phenolic substances in mustard.

Autoclaving increased phenolic content by $28.13 \%$ for ACLxBLM and by $22.14 \%$ and $26.35 \%$ for ACLxBRM and UNACLxYM, respectively. Similarly, in a number of studies, it is determinated that autoclaving increases the antioxidant activity

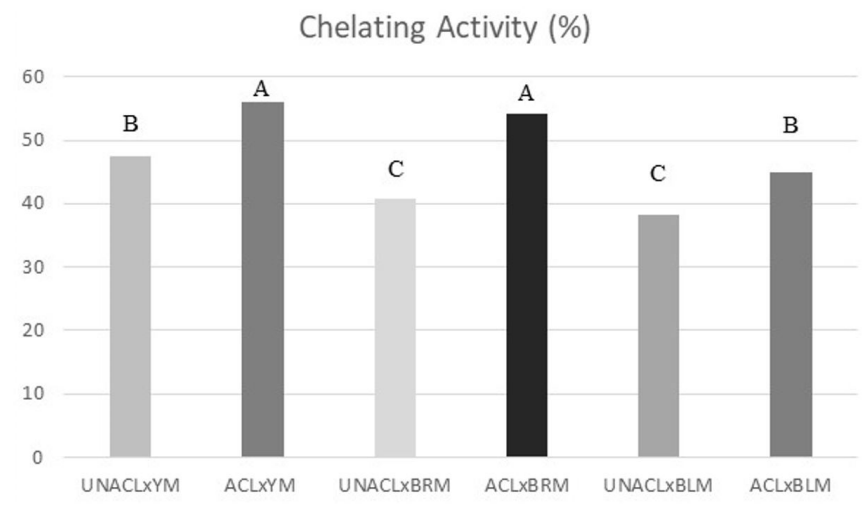

Figure 2. $\mathrm{Fe}^{+2}$ chelating activity of mustard types. Levels not connected by same letter are significantly different $(\mathrm{p}<0.05)$. The description of the sample codes is shown in Table 3.

$\mathrm{H}_{2} \mathrm{O}_{2}$ Inhibition Activity (\%)

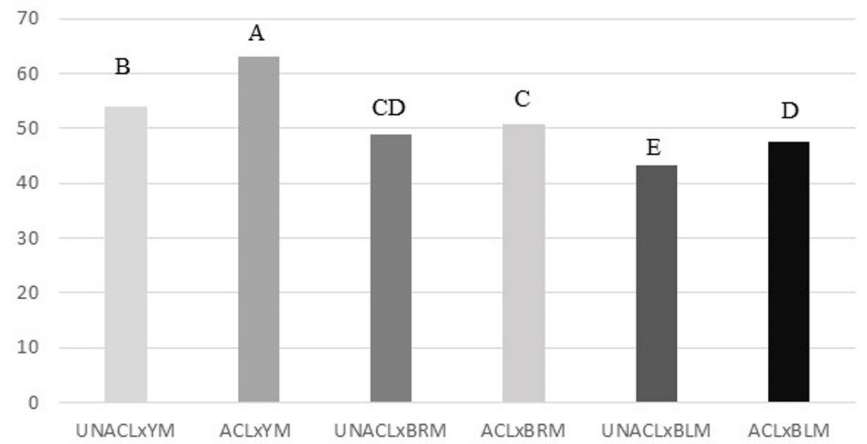

Figure 3. $\mathrm{H}_{2} \mathrm{O}_{2}$ inhibition activity of mustard types. Levels not connected by same letter are significantly different $(\mathrm{p}<0.05)$. The description of the sample codes is shown in Table 3.

Total phenolics compound (mg gallic acid/g)

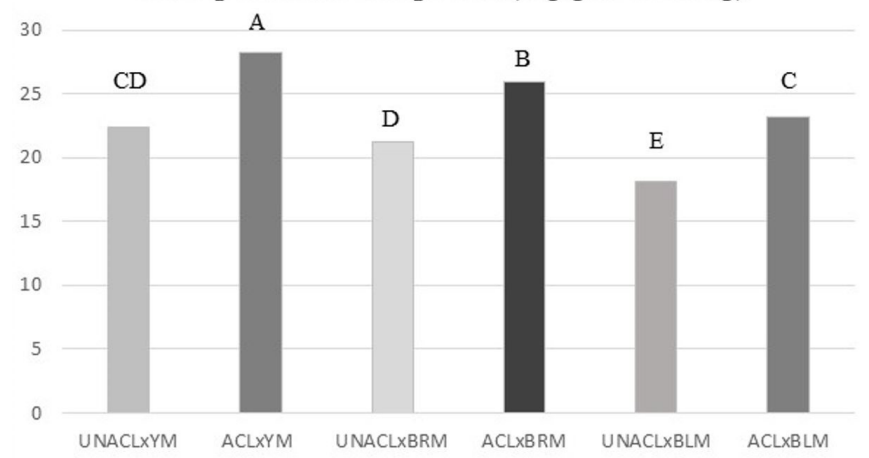

Figure 4. Total phenolics compound of mustard types (mg gallic acid/g). Levels not connected by same letter are significantly different $(p<0.05)$. The description of the sample codes is shown in Table 3. 
capacity of mustard. Luciano et al. (2011), in their study, reported that the autoclave application performed by Nilson \& Holley (2012) stabilized the level of mustard sinalbin (Luciano et al., 2011; Nilson \& Holley, 2012). Mustard autoclave application stabilized not only the sinalbin but also other glycosinates present in sinigrin.

\section{Conclusion}

This study proved that the autoclave process affect positively on phenolic acid and antioxidant capacity of mustard seeds. This treatment used to inhibit myrosinase activity. Therefore, myrosinase enzyme was inactivated and sinigrin, sinalbin content and phenolic content of mustard seeds were stabilized by this treatment. The mustard seeds wide range antioxidant capacity and they compared Sinapis alba generally has highest value all of the value. It may be originated from its phenolic content. Previous study (Çağlar et al., 2018) show that the addition of mustard seeds affected the TBARS value of meatball positively and this study supported by antioxidant capacity of mustard seeds. The mustard seeds are also good source of fiber, ash, oil and protein.

\section{Acknowledgements}

The authors would like to thank Afyon Kocatepe University for supporting this research (Project Number: 13.FEN.BİL.33).

\section{References}

Abul-Fadl, M. M., El-Badry, N., \& Ammar, M. S. (2011). Nutritional and chemical evaluation for two different varieties of mustard seeds. World Applied Sciences Journal, 15(9), 1225-1233.

Association of Official Analytical Chemists - AOAC. (2000). Official methods of analysis of the Association of Official Analytical Chemists (17th ed.). Washington: AOAC.

Bongoni, R., Verkerk, R., Steenbekkers, B., Dekker, M., \& Stieger, M. (2014). Evaluation of different cooking conditions on broccoli (Brassica oleracea var. italica) to improve the nutritional value and consumer acceptance. Plant Foods for Human Nutrition, 69(3), 228234. http://dx.doi.org/10.1007/s11130-014-0420-2. PMid:24853375.

Brand-Williams, W., Cuvelier, M. E., \& Berset, C. L. W. T. (1995). Use of a free radical method to evaluate antioxidant activity. LebensmittelWissenschaft + Technologie, 28(1), 25-30. http://dx.doi.org/10.1016/ S0023-6438(95)80008-5.

Çağlar, M. Y., Veli, G., Tomar, O., \& Akarca, G. (2018). Determination of the effect of different ground mustard seeds on quality characteristics of meatballs. Korean Journal for Food Science of Animal Resources, 38(3), 530-543. http://dx.doi.org/10.5851/kosfa.2018.38.3.530. PMid:30018497.

Cartea, M. E., Francisco, M., Soengas, P., \& Velasco, P. (2010). Phenolic compounds in Brassica vegetables. Molecules, 16(1), 251-280. http:// dx.doi.org/10.3390/molecules16010251. PMid:21193847.

Embuscado, M. E. (2015). Spices and herbs: natural sources of antioxidants: a mini review. Journal of Functional Foods, 18, 811-819. http://dx.doi. org/10.1016/j.jff.2015.03.005.

Engels, C., Schieber, A., \& Gänzle, M. G. (2012). Sinapic acid derivatives in defatted Oriental mustard (Brassica juncea L.) seed meal extracts using UHPLC-DAD-ESI-MS $\mathrm{n}$ and identification of compounds with antibacterial activity. European Food Research and Technology, 234(3), 535-542. http://dx.doi.org/10.1007/s00217-012-1669-z.

Fang, Z., Hu, Y., Liu, D., Chen, J., \& Ye, X. (2008). Changes of phenolic acids and antioxidant activities during potherb mustard (Brassica juncea, Coss.) pickling. Food Chemistry, 108(3), 811-817. http:// dx.doi.org/10.1016/j.foodchem.2007.11.033. PMid:26065739.

Jahangir, M., Kim, H. K., Choi, Y. H., \& Verpoorte, R. (2009). Healthaffecting compounds in Brassicaceae. Comprehensive Reviews in Food Science and Food Safety, 8(2), 31-43. http://dx.doi.org/10.1111/j.15414337.2008.00065.x.

Koç, Z. (2017). The effects of grape seed powder and extract on quality of fermented Turkish sausage. International Journal of Engineering and Techniques, 3(4), 140-145.

Lin, L. Z., \& Harnly, J. M. (2010). Phenolic component profiles of mustard greens, yu choy, and 15 other Brassica vegetables. Journal of Agricultural and Food Chemistry, 58(11), 6850-6857. http://dx.doi. org/10.1021/jf1004786. PMid:20465307.

Lombard, K., Peffley, E., Geoffriau, E., Thompson, L., \& Herring, A. (2005). Quercetin in onion (Allium cepa L.) after heat-treatment simulating home preparation. Journal of Food Composition and Analysis, 18(6), 571-581. http://dx.doi.org/10.1016/j.jfca.2004.03.027.

Lu, M., Yuan, B., Zeng, M., \& Chen, J. (2011). Antioxidant capacity and major phenolic compounds of spices commonly consumed in China. Food Research International, 44(2), 530-536. http://dx.doi. org/10.1016/j.foodres.2010.10.055.

Luciano, F. B., Belland, J., \& Holley, R. A. (2011). Microbial and chemical origins of the bactericidal activity of thermally treated yellow mustard powder toward Escherichia coli O157: H7 during dry sausage ripening. International Journal of Food Microbiology, 145(1), 69-76. http://dx.doi.org/10.1016/j.ijfoodmicro.2010.11.028. PMid:21146240.

Nilson, A. M., \& Holley, R. A. (2012). Use of deodorized yellow mustard powder to control Escherichia coli O157: H7 in dry cured Westphalian ham. Food Microbiology, 30(2), 400-407. http://dx.doi.org/10.1016/j. fm.2011.10.016. PMid:22365353.

Oram, R. N., Kirk, J. T. O., Veness, P. E., Hurlstone, C. J., Edlington, J. P., \& Halsall, D. M. (2005). Breeding Indian mustard [Brassica juncea (L.) Czern.] for cold-pressed, edible oil production: a review. Australian Journal of Agricultural Research, 56(6), 581-596. http:// dx.doi.org/10.1071/AR04295.

Park, S. Y., Jang, H. L., Lee, J. H., Choi, Y., Kim, H., Hwang, J., Seo, D., Kim, S., \& Nam, J. S. (2017). Changes in the phenolic compounds and antioxidant activities of mustard leaf (Brassica juncea) kimchi extracts during different fermentation periods. Food Science and Biotechnology, 26(1), 105-112. http://dx.doi.org/10.1007/s10068017-0014-5. PMid:30263516.

Peter, K. V. (2006). Handbook of herbs and spices (Vol. 3). Cambridge: Woodhead Publishing. http://dx.doi.org/10.1533/9781845691717.

Poyrazoğlu, E., Gökmen, V., \& Artık, N. (2002). Organic acids and phenolic compounds in pomegranates (Punica granatum L.) grown in Turkey. Journal of Food Composition and Analysis, 15(5), 567-575. http://dx.doi.org/10.1016/S0889-1575(02)91071-9.

Price, K. R., Bacon, J. R., \& Rhodes, M. J. (1997). Effect of storage and domestic processing on the content and composition of flavonol glucosides in onion (Allium cepa). Journal of Agricultural and Food Chemistry, 45(3), 938-942. http://dx.doi.org/10.1021/jf9605916.

Puupponen-Pimiä, R., Häkkinen, S. T., Aarni, M., Suortti, T., Lampi, A. M., Eurola, M., Piironen, V., Nuutila, A. M., \& Oksman-Caldentey, K. M. (2003). Blanching and long-term freezing affect various bioactive compounds of vegetables in different ways. Journal of the 
Science of Food and Agriculture, 83(14), 1389-1402. http://dx.doi. org/10.1002/jsfa.1589.

Rival, S. G., Boeriu, C. G., \& Wichers, H. J. (2001). Caseins and casein hydrolysates. 2. Antioxidative properties and relevance to lipoxygenase inhibition. Journal of Agricultural and Food Chemistry, 49(1), 295302. http://dx.doi.org/10.1021/jf0003911. PMid:11170591.

Ruch, R. J., Cheng, S. J., \& Klaunig, J. E. (1989). Prevention of cytotoxicity and inhibition of intercellular communication by antioxidant catechins isolated from Chinese green tea. Carcinogenesis, 10(6), 1003-1008. http://dx.doi.org/10.1093/carcin/10.6.1003. PMid:2470525.

Schuster, B., \& Herrmann, K. (1985). Hydroxybenzoic and hydroxycinnamic acid derivatives in soft fruits. Phytochemistry, 24(11), 2761-2764. http://dx.doi.org/10.1016/S0031-9422(00)80722-0.

Sharma, H. K., Ingle, S., Singh, C., Sarkar, B. C., \& Upadhyay, A. (2012). Effect of various process treatment conditions on the allyl isothiocyanate extraction rate from mustard meal. Journal of Food Science and Technology, 49(3), 368-372. http://dx.doi.org/10.1007/ s13197-011-0282-7. PMid:23729858.

Shui, G., \& Leong, L. P. (2002). Separation and determination of organic acids and phenolic compounds in fruit juices and drinks by highperformance liquid chromatography. Journal of Chromatography A, 977(1), 89-96. http://dx.doi.org/10.1016/S0021-9673(02)01345-6. PMid:12456098.

Singleton, V. L., \& Rossi, J. A. (1965). Colorimetry of total phenolics with phosphomolybdic-phosphotungstic acid reagents. American Journal of Enology and Viticulture, 16(3), 144-158.

Zhang, D., \& Hamauzu, Y. (2004). Phenolics, ascorbic acid, carotenoids and antioxidant activity of broccoli and their changes during conventional and microwave cooking. Food Chemistry, 88(4), 503509. http://dx.doi.org/10.1016/j.foodchem.2004.01.065. 